\title{
Peranan Gembala Sidang Dalam Pertumbuhan Iman Kaum Muda
}

\author{
Despri \\ Sekolah Tinggi Teologi Tenggarong \\ desprichristian@gmail.com \\ Yahya Usat \\ Sekolah Tinggi Teologi Tenggarong \\ johnusat1968@gmail.com
}

\begin{abstract}
:
The shepherd has a duty that must be accountable to God. The pastor is a leader who guides and guides the church so that the church experiences faith growth. In this effort the pastor needs to teach the stages of achieving it, and provide a correct understanding of faith. Thus the shepherd must play a full role in shepherding. The pastor's leadership is leadership based on the love of Christ not based on intimidation and oppression. Shepherds must be careful in applying the principles of leadership not to get caught up in the principles of secular leadership. Thus this study aims to examine the role of the pastor in the growth of the faith of young people. This research was conducted at the Indonesian Gospel Camp Long Pejeng Church, East Kutai Regency, East Kalimantan Province.
\end{abstract}

Key Words: Growth of Faith, Youth, Role of Shepherds, Pastoralism.

\begin{abstract}
Abstrak:
Gembala memiliki tugas yang harus dipertangungjawabkan kepada Allah. Gembala merupakan pemimpin yang membimbing dan menuntun jemaat agar jemaat mengalami pertumbuhan iman. Dalam upaya tersebut gembala perlu mengajarakan tahap-tahap mencapainya, dan memberi pemahaman yang benar tentang iman. Sehingga gembala sidang harus berperan penuh dalam penggembalaan. Kepemimpinan gembala merupkan kemimpinan yang berdasar atas kasih Kristus bukan berdasarkan pada pengintimidasian dan penindasan. Gembala harus berhati-hati dalam menerapkan prinsip-prinsip kepemimpinan jangan sampai terjebak dalam perinsip-prinsip kepemimpinan sekuler. Dengan demikian penelitian ini bertujuan untuk menguji peranan gembala sidang dalam pertumbuhan iman kaum muda. Penelitian ini dilaksanakan di Gereja Kemah Injil Indonesia Long Pejeng, Kabupaten Kutai Timur, Provinsi Kalimantan Timur.
\end{abstract}

Kata Kunci: Pertumbuhan Iman, Kaum Muda, Peranan Gembala, Penggembalaan.

\section{Pendahuluan}

Gembala berperan penting dalam penggembalaan jemaat, salah satunya ialah peran penggembalaan untuk kaum muda dalam upaya meningkatkan pertumbuhan iman kaum muda. Gembala tidak dapat hanya berfokus pada khotbah saja dalam pelayanan mimbar ketika ibadah, melainkan gembala perlu juga melakukan pendekatan khusus bagi kaum muda. Pertumbuhan iman dan kedewasaan jemaat merupakan tanggungjawab gembala sebagai pemimpin gereja (Widiyanto, 2020). Gembala diutus oleh Allah untuk melaksanakan tugas amanat agung. Sehingga gembala memiliki tugas 
tanggungjawab besar selain kepada umat Allah, gembala juga mempertangungjawabkan tugasnya kepada Allah yang sebagai pemberi tugas (Kosta \& Djadi, 2011). Gembala diberi tugas dari Allah dan mengerjakan tugas tanggungjawabnya apapun rintangannya, karena gembala pada akhirnya akan mempertangungjawabkan tugasnya kepada Allah. Gembala melayani Allah harus dengan kesungguhan hatinya setiap saat. Gembala mendapatkan tanggungjawab dari Allah untuk menggembalakan, memelihara, menjaga dan mengawasi jemaat secara kualitas maupun kuantitas yang Allah telah percayakan. Peranan gembala bukan hanya memimpin tetapi juga memelihara seluruh anggota jemaat gereja maupun orang lain, gembala juga memberitakan injil sesuai dengan isi seluruh Firman Allah (Telaumbanua, 2019). (Santo \& Simanjuntak, 2019) menyatakan bahwa penggembalaan tidak dapat dipisahkan dari tugas-tugas dan pelayanan gereja. Untuk menumbuhkan iman jemaat, penggembangan gereja dan menjadikan gereja yang mandiri dibutuhkan penggembalaan yang baik untuk mencapai tujuan tersebut. Untuk menjawab setiap kebutuhan jemaat, peranan gembala ialah memberi kehangatan, perhatian dan dukungan bagi jemaat yang mau bertumbuh dalam iman dan belum bertumbuh agar bertumbuh. Yesus telah memberikan teladan bagaimana seharusnya menjadi seorang gembala yang baik. Yesus sebagai gembala yang baik telah merawat dan memelihara manusia yang berdosa dengan sepenuh hati agar bertobat meninggalkan kejahatan, bahkan Yesus rela mengorbankan nyawa demi manusia yang berdosa (Yoh. 10:11). Penggembalaan seorang gembala merupakan kepemimpinan mengorganisasi sekaligus seorang pelayanan yang menyediakan kebutuhan-kebutuhan jemaat dalam upaya meningkatkan pertumbuhan iman. Seorang gembala tidak bisa menyamakan kepemimpinannya seperti kepemimpinan pada dunia sekuler. Ipaq (Ipaq, 2014) menyatakan bahwa kepemimpinan gembala ialah berdasarkan kasih Kristus yang mengutamakan nilai-nilai rohani sebagai suatu konsep pendekatan kepada jemaat dalam kepemimpinan, moralitas, sosial dan etika. Oleh karena itu kepemimpinan seorang gembala bukan untuk kekuasaan, politik dan materi (Yohanes 21:15-17), Allah memberikan kuasa kepada gembala bukan untuk memerintah, tetapi bertindak bersamasama jemaat untuk saling melayani satu sama lain terlebih kepada Allah. Daud mengatakan "Tuhan gembala yang baik" (Mazmur 23:1-6), karena Allah telah lebih dahulu melayani manusia.

Gembala merupakan pengajar dan pembimbing bagi jemaat sehingga gerejanya mengalami pertumbuhan iman. Menurut Tafonao tugas peranan gembala salah satunya ialah mengajar. Mengajar merupakan tugas penting dalam pengembalaan, oleh karena itu gembala harus mampu menyiapkan, merangkai atau menyusun strategi dengan baik agar isi dari Firman Tuhan tersampaikan secara baik dan benar. Menurutnya gembala yang baik adalah gembala yang mengenal jemaat yang sedang dilayani. Gembala yang baik mampu mengenal jemaatnya secara utuh dan memiliki hubungan emosional yang 
baik dengan jemaat yang sedang digembalakan. Tugas seorang gembala selain mengajar ialah sebagai motivator bagi jemaatnya, supaya jemaat yang dilayani memiliki arah tujuan yang jelas dan sesuai dengan kehendak Allah bagi pertumbuhan iman jemaat sehari-hari (Tafonao, 2018). Pembentukan pada diri seorang gembala adalah bekal untuk mengembalakan serta dibutuhkan metal yang kokoh, sebab seorang gembala selain memberi makan domba-Nya, seorang gembala harus memiliki pemahaman dan pengetahuan yang benar tentang tugas yang ia kerjakan, sehingga ia dapat mengarahkan domba-domba-Nya sampai dewasa didalam Tuhan. Dalam Injil Yohanes 10:11 Yesus menyatakan : "Akulah Gembala yang baik". Artinya bahwa gembala yang baik ialah gembala yang mengenal jemaat yang dilayani dan jemaat mengenal Dia yang melayani. Gereja bertumbuh karena diperkuat kecerdasannya, jasmaninya, kerohaniannya dan kehidupan sosialnya, sehingga ia makin disukai oleh Allah dan manusia (Takaliuang, 2012). Dalam pertumbuhan gereja yang utuh dan menyeluruh, maka ketiga aspek kebutuhan manusia, yaitu: kebutuhan kepala, hati dan perut harus dipenuhi agar tubuh itu dapat tumbuh seimbang dan selaras. Oleh karena itu, seorang gembala harus bertanggung jawab untuk menjaga kehidupannya sendiri bersama Tuhan sehingga ia akan berpikir, berbicara, bertindak dan mengasihi lebih sesuai dengan kehidupan Tuhan Yesus dalam dirinya dari pada menurut sifat kedangingannya sendiri. Di satu pihak ia harus menjadi teladan yang hidup dari kehidupan Kristus dan mengikuti nasihat Paulus kepada Timotius untuk "menjadi teladan bagi orang-orang percaya" (I Timotius 4:12). Di pihak lain, ia tidak boleh menipu dirinya sendiri dengan mengira bahwa ia kebal terhadap cobaan atau bahwa dalam segala hal ia lebih unggul dari pada orang yang di bimbing. Roh kelemahlembutan dan kebergantungan kepada Tuhan sangat penting sebab seorang pembimbing mungkin di cobai untuk mengira bahwa ia mampu menolong orang lain karena kabaikan dan kemampuannya sendiri. Karena seorang pembimbing Alkitabiah mewakili Allah dalam bimbingan, ia harus hidup secara terus menerus menurut Galatia 2:20 (Bobgan et al., 1985). Allah menginginkan jemaat-Nya mencapai pertumbuhan iman sempurna dalam tindakan yang sehat. Dalam kitab Efesus 4:11-16 Allah memperlengkapi orang-orang kudus untuk mencapai kesatuan iman dan pemahaman yang benar tentang Anak Allah. Sebagai pembuktian kesatuan pertumbuhan iman yang sempurna dalam nats ini ialah sampai, mencapai, dan sehingga. Ketiga kata ini memiliki pengertian dan pemahaman yang sama, yaitu dari satu titik tolak tertentu menuju ke satu titik tolak berikutnya. Hal ini merupakan dinamika, progres yang terus menerus yang jelas dan terarah menuju kepada sesuatu yang lebih baik, lebih tinggi, lebih mulia dan yang sempurna (Basuki, 2014).

Pada kenyataanya gembala justru lebih memperhatikan hal-hal yang berskala besar daripada hal-hal berskala kecil. Gembala lebih mementingkan fasilitas, pembangunan gedung gereja dan berkhotbah tentang kedewasaan iman, tanpa memperhatikan kebutuhan-kebutuhan finansial dan tahap-tahap untuk mencapai pertumbuhan iman menuju kedewasaan iman jemaat. Beberapa kasus yang terjadi dalam jemaat ialah gembala yang kurang cakap dalam merealisasikan tugas 
penggembalaan, sehingga kehadiran gembala menimbulkan persoalan baru dalam jemaat. Gembala seharusnya mau belajar dan memiliki hati seperti Yesus Kristus yaitu melayani dengan sikap hati tulus. Gembala yang tidak memiliki hati sebagai pelayan ialah gembala yang mengutamakan materi finansial untuk kepentingan pribadi gembala dan menjadikan jemaat sebagai ladang pendapatan tanpa memperhatikan kebutuhankebutuhan rohani jemaat. Selain itu, jika pemahaman seorang istri gembala tidak memahami dengan benar arti dari pelayanan rohani, maka dalam pelayanan penggembalaan istri akan menuntut dilayani bukan untuk melayani selayaknya perilaku istri seorang gembala terhadap jemaat (Ipaq, 2014). Selain pengaruh peran yang buruk dari gembala, pengaruh media sosial dikalangan kaum muda juga sangat berdampak. Penggunaan media sosial tidak lepas dari dampak yang positif maupun negatif. Sehingga dampak tersebut tergantung dari penggunanya sendiri. Pemanfaatan media sosial memiliki pengaruh yang sangat besar terhadap pertumbuhan rohani generasi muda. Sehingga banyak generasi muda yang kehidupannya rusak dan tingkat kerohaniannya rendah karena dipengaruhi oleh media sosial (Hutahayan, 2019). Dengan demikian gembala harus benar-benar memiliki hati yang tulus dalam melaksanakan tugas penggembalaan, seperti Yesus Kristus. Peran gembala bukanlah mengutamakan kepentingan-kepentingan pribadi yang bersifat merugikan jemaat, tetapi peran gembala ialah mengutamakan kepentingan bersama yang bertujuan untuk meningkatkan iman jemaat.

Rumusan masalah ini adalah apakah terdapat peranan gembala sidang dalam pertumbuhan iman kaum muda signifikan? Sedangkan tujuan dari penelitian ini adalah untuk menguji dan mendeskripsikan peranan gembala sidang dalam pertumbuhan iman pemuda.

\section{Metode}

Metode penelitian yang digunakan adalah korelasional yang bertujuan untuk mengetahui hubungan antar variabel penelitian. Populasi penelitian ini adalah pemuda di Gereja Kemah Injil Indonesia (GKII) Long Pejeng, Kabupaten Kutai Timur, Kalimantan Timur, yang bejumlah 102. Dalam penelitian ini populasi yang di ambil sebagai sampel sebanyak 20 orang.

Teknik pengambilan data dilakukan dengan menggunakan kuesioner dengan model tertutup, dimana telah disediakan alternatif jawaban untuk setiap pernyataan penelitian dengan model skala perilaku. Jumlah opsi alternatif pilihan jawaban sebanyak lima, yaitu Sangat Sering (SS), Sering (S), Kadang-Kadang (KK), Pernah (P), Tidak Pernah (TP). Pengembangan instrumen penelitian didasarkan pada pengembangan teori tentang peranan gembala dan pertumbuhan iman. Berdasarkan konstruk untuk setiap variabel penelitian kemudian disusun instrumen penelitian berupa kuesioner. Intrsumen perenan gembala dalam pembinaan pemuda terdiri dari 12 item yang semuanya valid dengan koefisien reliabilitas sebesar 0,822. Sedangkan instrumen pertumbuhan iman 
pemuda terdiri dari 12 item yang semuanya valid dengan koefisien reliabilitas sebesar 0.844 .

Teknik analisis dalam menjawab rumusan masalah dan pengujian hipotesis dalam penelitian ini menggunakan analisis kolerasi sederhana dan regresi sederhana. Widiyanto (2014) menyatakan analisa korelasi digunakan untuk mencari hubungan diantara dua variabel atau lebih. Variabel dalam penelitian ini ialah peranan dan pertumbuhan iman.

\section{Hasil}

Berdasarkan data yang dianalisis, dihasilkan analisis deskriptif untuk masingmasing variabel sebagai berikut:

\begin{tabular}{|l|r|r|r|r|r|}
\hline \multicolumn{7}{|c|}{ Descriptive Statistics } \\
\hline & N & Minimum & Maximum & Mean & Std. Deviation \\
\hline Peranan Gembala & 20 & 35 & 57 & 48,35 & 6,020 \\
\hline Pertumbuhan Iman & 20 & 27 & 47 & 34,90 & 5,447 \\
\hline
\end{tabular}

Berdasarkan tabel 1 menunjukkan bahwa dari pengisian instrumen penelitian untuk variabel peranan gembala besarnya nilai empiris minimum sebesar 35 dan nilai maksimum sebesar 57. Besarnya nilai rata-rata sebesar 48,35 dengan nilai simpangan baku sebesar 6,020. Hasil analisis menunjukkan bahwa sebanyak 9 orang atau $45 \%$ yang memperoleh skor berada di bawah rata-rata dan sebanyak 11 orang atau 55\% yang memperoleh skor di atas rata-rata. Dengan demikian peranan gembala dalam pembinaan pemuda dapat dikategorikan cukup baik.

Berdasarkan tabel 1 menunjukkan bahwa dari pengisian instrumen penelitian untuk variabel pertumbuhan iman besarnya nilai empiris minimum sebesar 27 dan nilai maksimum sebesar 47. Besarnya nilai rata-rata sebesar 34,90 dengan nilai simpangan baku sebesar 5,447. Hasil analisis menunjukkan bahwa sebanyak 8 orang atau $40 \%$ yang memperoleh skor berada di bawah rata-rata dan sebanyak 12 orang atau $60 \%$ yang memperoleh skor di atas rata-rata. Dengan demikian pertumbuhan iman pemuda dapat dikategorikan cukup baik.

Berdasakan analisis peranan gembala sidang dalam pertumbuhan iman kaum muda dengan analisis korelasi sederhana dan regresi sederhana, diperoleh hasil sebagai berikut: 


\begin{tabular}{|c|c|c|c|c|c|c|}
\hline \multicolumn{7}{|c|}{ Coefficients $^{\mathrm{a}}$} \\
\hline & \multirow[b]{2}{*}{ Model } & \multicolumn{2}{|c|}{$\begin{array}{l}\text { Unstandardized } \\
\text { Coefficients } \\
\end{array}$} & \multirow{2}{*}{$\begin{array}{c}\text { Standardized } \\
\text { Coefficients }\end{array}$} & \multirow[b]{2}{*}{$\mathrm{T}$} & \multirow[b]{2}{*}{ Sig. } \\
\hline & & $\mathrm{B}$ & Std. Error & & & \\
\hline \multirow[t]{2}{*}{1} & (Constant) & 20,807 & 9,834 & & 2,116 &, 049 \\
\hline & Peranan Gembala & ,291 & ,202 & ,322 & 1,444 & 166 \\
\hline
\end{tabular}

Sumber: Data penelitian

Tabel 2. Hasil Analisis Regresi dan Uji Signifikansi Persamaan Regresi

\begin{tabular}{|l|l|r|r|r|c|c|}
\hline \multicolumn{7}{|c|}{ ANOVA $^{\mathbf{a}}$} \\
\hline \multirow{2}{*}{ Model } & $\begin{array}{c}\text { Sum of } \\
\text { Squares }\end{array}$ & \multicolumn{1}{c|}{ Df } & Mean Square & F & Sig. \\
\hline 1 & Regression & 58,500 & 1 & 58,500 & 2,084 &, $166^{\mathrm{b}}$ \\
\cline { 2 - 7 } & Residual & 505,300 & 18 & 28,072 & & \\
\cline { 2 - 7 } & Total & 563,800 & 19 & & & \\
\hline \multicolumn{2}{|l}{ a. Dependent Variable: Pertumbuhan Iman } \\
\hline
\end{tabular}

Sumber: Data Penelitian

Tabel 3. Hasil Uji Signifikansi Persamaan Regresi

Dari hasil perhitungan pada tabel di atas diperoleh bahwa $\mathrm{F}_{\text {hitung }}$ sebesar 2,084 dengan P-value (sig.) 0,166. Oleh karena itu P-value $<0,05$ (taraf signifikan) yang memiliki arti bahwa persamaan regresi tersebut signifikan, maka dapat disimpulkan bahwa persamaan regresi $\hat{Y}=20,807+0,291 X$ adalah berarti. Karena persamaan regresinya linear berarti, maka dapat digunakan untuk memprediksi bahwa regresi ini mengandung arti apabila skor rata-rata pertumbuhan iman akan meningkat sebesar 0,291 pada konstanta 20,807. Sedangkan hasil analisis korelasi peranan gembala sidang dalam pertumbuhan iman kaum muda menggunakan korelasi Pearson Product Moment menunjukkan bahwa:

\begin{tabular}{|c|c|c|c|c|}
\hline \multicolumn{5}{|c|}{ Model Summary } \\
\hline Model & $\mathrm{R}$ & R Square & $\begin{array}{c}\text { Adjusted R } \\
\text { Square }\end{array}$ & $\begin{array}{l}\text { Std. Error of } \\
\text { the Estimate }\end{array}$ \\
\hline 1 & $322^{\mathrm{a}}$ & 104 & , 054 & 5,298 \\
\hline
\end{tabular}

Sumber: Data penelitian

Tabel 3. Hasil Analisis Korelasi

Berdasarkan kedua tabel di atas besarnya koefisien kolerasi sebesar 0,322 dan

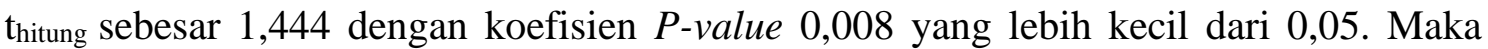


disimpulkan bahwa terdapat pengaruh yang signifikan peranan gembala sidang dalam pertumbuhan iman kaum muda. Besarnya koefisien determinasi $\left(r^{2}{ }_{y x}\right)$ sebesar 0,054 mempunyai makna bahwa peranan gembala sidang dalam pertumbuhan iman kaum muda sebesar 5,4\%, sedangkan sisanya sebesar 94,6\% dipengaruhi oleh faktor lain yang tidak diteliti.

\section{Pembahasan}

Hasil penelitian ini menunjukkan bahwa peranan gembala sidang berpengaruh dalam pertumbuhan iman kaum muda. Berdasarkan penelitian tersebut, hasil ini sesuai dengan (Tafonao, 2018) yang menyatakan bahwa gembala yang memiliki kompentensi dalam mengajar dan memotivasi kaum muda sangat dibutuhkan oleh gereja masa kini. Gembala yang berkompetensi dalam mengajar dan memotivasi kaum muda akan sangat membantu kaum muda untuk mengalami pembaruan hidup dan memiliki kedewasan baik secara iman maupun intelektual. Kemampaun kaum muda sangat besar dan dapat menentukan tujuan gereja dimasa yang akan datang. Maka dari itu, kemampuan kaum muda penting untuk diarahkan dan dimanfaatkan dengan sebaik mungkin guna menjadi tulang punggung gereja dimasa yang akan datang dan menjadi dewasa secara intelektual dan keimanan. Gembala harus jeli menangkap sinyal-sinyal yang terjadi pada kaum muda, secara sadar maupun tidak kaum muda mengalami kemerosatan moral dan iman dilingkungan gereja masa kini, sehingga tidak sedikit kaum muda meninggalkan imannya hanya karena gembala kurang peka terhadap pertumbuhan iman kaum muda (Tafonao, 2018). Ketika gembala berkotbah di mimbar, tidak semua jemaat bisa menangkap dengan baik dan benar tentang apa yang dikhotbahkan oleh gembala, maka dari itu perkunjungan pastoral merupakan tindakan kreatif untuk memberitakan firman Allah secara detail. Pemberitaan firman Allah melalui perkunjungan pastoral dapat membantu gembala untuk memahami kemampuan jemaatnya dalam memahami firman Allah. Dengan demikian gembala bisa memberi pengajaran yang bertahap menyesuaikan pemahaman jemaatnya melalui perkunjungan. Sesuai dengan pernyataan Widiyanto yang menyatakan bahwa perkunjungan ke tempat-tempat jemaat adalah salah satu pelayanan yang bertujuan untuk mengenali jemaat dengan lebih baik dan dekat. Dengan demikian hubungan antara gembala dan jemaat tidak ada kesenjangan, sehingga jemaat berani untuk terbuka dalam menyampaikan persoalan-persoalan yang mereka alami. Pertumbuhan iman kaum muda dapat ditingkatkan melalui perkunjungan pastoral. Pelayanan ini ialah pelayanan penggembalaan yang bertujuan untuk membina kehidupan rohani kaum muda. Sehingga gembala tidak boleh mengabaikan pelayanan ini. Hubungan gembala dan kaum muda menentukan kehidupan rohani kaum muda. Apabila gembala mengabaikan perannya sebagai pembimbing dan penuntun jemaat 
maka gereja yang dipimpin oleh gembala tidak bertumbuh dalam Kristus (Widiyanto, 2020).

Melalui hasil penelitian ini, dapat diketahui juga bahwa peran gembala dalam meningkatkan pertumbuhan iman kaum muda harus benar-benar diperhatikan secara menyeluruh, bukan hanya memilih kaum muda yang aktif dalam ibadah di gereja untuk dilayani tetapi juga yang kurang aktif bahkan yang tidak pernah sekalipun. Gembala adalah pemimpin dipercayakan oleh Allah untuk menjadi perawat dan pemelihara jiwa manusia (Telaumbanua, 2019). Dalam upaya meningkatkan pertumbuhan iman kaum muda selain perkunjungan pastoral, gembala juga harus menjadi seorang yang mau mendengarkan apa yang dialami oleh jemaat. Dengan mengetahui hal-hal yang terjadi dalam jemaat, maka pelayanan gembala tertolong dan pelayanan gembala sidang bisa menyesuaikan dengan apa yang terjadi dalam jemaat. Usat menyatakan Pemimpin yang mau mendengar adalah pemimpin yang aspiratif, turun gunung (takhta) melakukan blusukan, hadir di tengah-tengah orang yang dipimpin, menyerap aspirasi dan keluhan mereka dan bercengkraman dengan mereka dan bahkan menjadi pelayan bagi mereka. Yesus mengatkan kepada murid-murid-Nya, bahwa barang siapa yang ingin menjadi besar di antara kamu, hendaklah ia menjadi pelayanmu, dan barang siapa yang ingin terkemuka di antara kamu, hendaklah ia menjadi hambamu (Matius 20:27). Menurut Usat kepemimpinan sesungguhnya bukanlah sebuah kekuasaan di mana pemimpin menempatkan dirinya sebagai penguasa dan memerintah dengan semena-mena atas orang yang dipimpin. Falsafah untuk menjadi orang besar dan terkemuka menurut Yesus adalah menjadi pelayan atau hamba bagi orang yang dipimpin (Usat, 2019).

Disisi lain hasil penelitian ini sejalan dengan Gideon yang menyatakan bahwa dalam kepemimpinan ada suatu pemberdayaan yang mana tujuannya untuk memproses atau mengolah kemampuan yang dimiliki setiap individu jemaat sesuai dengan kemamuan mereka masing-masing yang telah digali potensi-potensi yang terdapat dalam diri jemaat. Peran gembala adalah membantu jemaat mencapai kedewasaan rohani yang Allah sediakan bagi mereka (Gidion, 2018). Dengan demikian gembala harus melaksankan perannya dengan sebaik-baiknya, sebab peran gembasla sidang menentukan kualitas pertumbuhan iman kaum muda.

\section{Kesimpulan}

Hasil pengujian diperoleh bahwa terdapat peranan gembala dalam pertumbuhan iman kaum muda yang ditunjukkan melalui koefisien kolerasi sebesar 0,322 yang signifikan pada $\alpha=0,05$. Berdasarkan hasil analisis menunjukkan bahwa peranan gembala sidang memiliki pengaruh terhadap pertumbuhan iman kaum muda. Semakin baik dan intens peran gembala sidang akan berdampak pada pertumbuhan iman kaum muda. 
Saran bagi gembala sidang, gembala harus menyadari kebutuhan dalam pelayanan. Kebutuhan pelayanan bukan hanya secara finansial dalam jemaat maupun pribadi, tetapi juga secara kerohanian jemaat terutama bagi kaum muda. Kaum muda merupakan penerus perjuangan Kristus maupun penyalur cahaya dan berkat Kasih Allah bagi banyak orang di masa yang akan datang. Peran gembala merupakan langkah awal untuk menentukan perubahan bagi langkah kaum muda di masa yang akan datang. Peran gembala di dalam kerohanian merupakan tugas dan tanggung jawab seorang pelayan Allah yang telah di tugaskan. Peran gembala bukan hanya sebagai pembimbing, tetapi juga sebagai pemeliharan iman. Peran gembala ialah memahami dan menemukan setiap masalah-masalah kaum muda secara individu, agar secara pribadi kaum muda merasa diperhatikan oleh gembala.

Peran gembala bagi kaum muda bukan menjadi hakim bagi kesalahan mereka tetapi gembala berperaan sebagai penolong yang memberi solusi sesuai dengan Alkitab. Peran gembala bukan sekedar membina dan menjaga kaum muda yang aktif dalam gereja, peran gembala juga mencari kaum muda yang tidak pernah aktif lagi datang ke gereja. Peran gembala bagi jemaat bukan sebagai penguasa yang mengontrol semua aspek kehidupan jemaatnya, peran gembala adalah untuk membina, mengarahkan, mengajarkan dan menuntun jemaatnya dengan baik sesuai dengan teladan Yesus Kristus. Gembala tidak bisa langsung memaksakan jemaatnya untuk memahami pemahaman tentang Alkitab yang sulit. Gembala bisa mengajarkan jemaatnya tahap demi tahap untuk mengerti pemahaman Alkitab, sehingga jemaat tidak tersesat karena salah penafsiran dan pemahaman. Gembala harus memiliki pemahaman yang luas dalam memberitakan kebenaran firman Allah, sebab Alkitab begitu sarat akan pengajaran, pemahaman dan pengertiannya sehingga gembala dalam mempelajari Alkitab harus berhati-hati dan jangan gegabah dalam mempersiapkan khotbah.

\section{Daftar Rujukan}

Basuki, Y. E. (2014). Pertumbuhan Iman Yang Sempurna: Menumbuhkan Iman Sesuai Kehendak Allah. Garudhawaca Online Books.

Bobgan, Bobgan, M., Tan, D., \& Lie, G. (1985). Membimbing berdasarkan firman Allah. Yayasan Kalam Hidup.

Gidion, G. (2018). Efektifitas Kepemimpinan Yang Memberdayakan Dalam Meningkatkan Pertumbuhan Gereja Di Gereja Jemaat Kristen Indonesia Maranatha Ungaran. Shift Key: Jurnal Teologi dan Pelayanan, 8(1), 36-37. https://doi.org/10.37465/shiftkey.v8i1.14

Hutahayan, B. (2019). Peran Kepemimpinan Spiritual Dan Media Sosial Pada Rohani Pemuda. Deepublish. 
Ipaq, E. W. (2014). Pemahaman Terhadap Pemimpin Gembala Pemimpin Gembala Dalam Pengertian Dogma Alkitabiah : Jurnal Jaffray, 15-17.

Kosta, Y., \& Djadi, J. (2011). Peranan Gembala Sebagai Pemimpin Dalam Perspektif I Petrus 5:1-4 Dan Relevansinya Pada Masa Kini. Jurnal Jaffray, 9(2), 172. https://doi.org/10.25278/jj71.v9i2.100

Santo, J. C., \& Simanjuntak, D. T. (2019). Pengaruh Keteladanan Hidup Gembala Sidang terhadap Pertumbuhan Gereja. KHARISMATA: Jurnal Teologi Pantekosta, 2(1), 28-41.

Tafonao, T. (2018). Peran Gembala Sidang Dalam Mengajar Dan Memotivasi Untuk Melayani Terhadap Pertumbuhan Rohani Pemuda. Evangelikal: Jurnal Teologi Injili dan Pembinaan Warga Jemaat, 2(1), 36-49. https://doi.org/10.46445/ejti.v2i1.85

Takaliuang, M. P. (2012). Faktor-faktor Penghambat dan Penunjang Pertumbuhan Gereja. 27.

Telaumbanua, A. (2019). Peran Gembala Sidang Sebagai Pendidik Dalam Pertumbuhan Rohani Jemaat. FIDEI: Jurnal Teologi Sistematika dan Praktika, 2(2), 362-387. https://doi.org/10.34081/fidei.v2i2.45

Usat, Y. (2019). Kepemimpinan Blusukan: Model Kepemimpinan Kristen Yang Membumi. 1, 93-100.

Widiyanto, M. A. (2014). Statistika Untuk Penelitian Bidang Teologi, PAK dan Pelayanan Gerejawi. Yayasan Kalam Hidup.

Widiyanto, M. A. (2020). Pengaruh Pelayanan Kunjungan Pastoral Terhadap Pertumbuhan Rohani Jemaat. Evangelikal: Jurnal Teologi Injili dan Pembinaan Warga Gereja, 4(1), 39-46. 